\title{
Climate change impacts on rainfall extremes and urban drainage: state-of-the-art review
}

Patrick Willems (1), Jonas Olsson (2), Karsten Arnbjerg-Nielsen (3), Simon Beecham (4), Assela Pathirana (5), Ida Bülow Gregersen (6), Henrik Madsen (7), and Van-Thanh-Van Nguyen (8)

(1) University of Leuven, Hydraulics division, Kasteelpark Arenberg 40, BE-3001 Leuven, Belgium (Patrick.Willems@bwk.kuleuven.be), (2) Swedish Meteorological and Hydrological Institute, Research \& Development (hydrology), SE-601 76 Norrkoping, Sweden (jonas.olsson@smhi.se), (3) Technical University of Denmark, Department of Environmental Engineering, DK-2800 Lyngby, Denmark (kan@env.dtu.dk), (4) University of South Australia, School of Natural and Built Environments, North Terrace, Adelaide, South Australia 5000, Australia (simon.beecham@unisa.edu.au), (5) UNESCO-IHE Institute for Water Education, Westvest 7, 2611 AX Delft, The Netherlands (a.pathirana@unesco-ihe.org), (6) Technical University of Denmark, Department of Environmental Engineering, DK-2800 Lyngby, Denmark (idbg@env.dtu.dk), (7) DHI Water \& Environment, Water Resources Department, DK-2970 Hørsholm, Denmark (hem@dhigroup.com), (8) Mc Gill University, Department of Civil Engineering and Applied Mechanics, Montreal, Quebec, Canada H3A 2K6 (van.tv.nguyen@mcgill.ca)

Under the umbrella of the IWA/IAHR Joint Committee on Urban Drainage, the International Working Group on Urban Rainfall (IGUR) has reviewed existing methodologies for the analysis of long-term historical and future trends in urban rainfall extremes and their effects on urban drainage systems, due to anthropogenic climate change. Current practises have several limitations and pitfalls, which are important to be considered by trend or climate change impact modellers and users of trend/impact results.

The review considers the following aspects:

Analysis of long-term historical trends due to anthropogenic climate change: influence of data limitation, instrumental or environmental changes, interannual variations and longer term climate oscillations on trend testing results.

Analysis of long-term future trends due to anthropogenic climate change: by complementing empirical historical data with the results from physically-based climate models, dynamic downscaling to the urban scale by means of Limited Area Models (LAMs) including explicitly small-scale cloud processes; validation of $\mathrm{RCM} / \mathrm{GCM}$ results for local conditions accounting for natural variability, limited length of the available time series, difference in spatial scales, and influence of climate oscillations; statistical downscaling methods combined with bias correction; uncertainties associated with the climate forcing scenarios, the climate models, the initial states and the statistical downscaling step; uncertainties in the impact models (e.g. runoff peak flows, flood or surcharge frequencies, and CSO frequencies and volumes), including the impacts of more extreme conditions than considered during impact model calibration and validation.

Implications for urban drainage infrastructure design and management: upgrading of the urban drainage system as part of a program of routine and scheduled replacement and renewal of aging infrastructure; how to account for the uncertainties; flexible and sustainable solutions; adaptive approach that provides inherent flexibility and reversibility and avoids closing off options; importance of active learning.

References:

Willems, P., Olsson, J., Arnbjerg-Nielsen, K., Beecham, S., Pathirana, A., Bülow Gregersen, I., Madsen, H., Nguyen, V-T-V. (2012). Impacts of climate change on rainfall extremes and urban drainage. IWA Publishing, 252 p., Paperback Print ISBN 9781780401256 ; Ebook ISBN 9781780401263

Willems, P., Arnbjerg-Nielsen, K., Olsson, J., Nguyen, V.T.V. (2012), 'Climate change impact assessment on urban rainfall extremes and urban drainage: methods and shortcomings', Atmospheric Research, 103, 106-118 